\title{
Edmonton Symptom Assessment System
}

National Cancer Institute

\section{Source}

National Cancer Institute. Edmonton Symptom Assessment System. NCI Thesaurus.

Code C107391.

A self-report assessment tool to screen for the intensity of nine symptoms commonly experienced by cancer patients in palliative care. 